\title{
A Prospective Comparative Study of Both Bone Forearm Fracture in Patients above Twelve Years of Age Treated with Dynamic Compression Plating and Intramedullary Nailing at a Tertiary Care Hospital in Kurnool, Andhra Pradesh
}

\author{
A.M. Ilias Basha ${ }^{1}$, Chandan S.2 ${ }^{2}$ Gajendra ${ }^{3}$ \\ 1,2,3 Department of Orthopaedics, Kurnool Medical College, Kurnool, Andhra Pradesh, India.
}

\section{ABSTRACT}

\section{BACKGROUND}

The incidence of forearm fractures is increasing faster than the usual predicted rate due to rapid industrialization, increased incidence of motor vehicle accident and various sports activities and increase in the incidence of fall and direct blow. For pronation and supination to occur, the maintenance of interosseous space becomes mandatory while fixing the fractures involving radius and ulna. ${ }^{1}$ Both bone forearm fractures are not uncommon. Healing occurs reliably after closed treatment but malunion with resultant decreased rotation of the forearm is common and has been associated with poor results. ${ }^{2,3}$ The purpose of this study was to analyse functional outcome of both bone forearm fracture in patients above 12 years of age treated with dynamic compression plating and intramedullary nailing.

\section{METHODS}

This is a prospective comparative study of 30 cases of diaphyseal fracture of both bones of forearm who attended casualty and out-patient department (OPD) of Government General Hospital, Kurnool and were treated by surgical fixation with dynamic compression plating and intramedullary nailing between November 2018 to November 2020.

\section{RESULTS}

The functional outcome as per modified grace eversmann scoring system in dynamic compression plating (DCP) group was that $80 \%$ (12 patients) had excellent results, $20 \%$ (3 patients) had good results with no patient having fair and poor results. In the intramedullary nailing (IMN) group, $66.7 \%$ (10 patients) had excellent results, $13.3 \%$ (2 patients) had good results, $13.3 \%$ (2 patients) had fair results and $6.7 \%$ (1 patient) had poor result.

\section{CONCLUSIONS}

Even though plate osteosynthesis is still the most commonly used form of fixation in both bone forearm fractures, titanium elastic nail and intramedullary nail fixation are relatively newer techniques which offer viable and more efficient alternative especially in fixation of fractures involving shafts of radius and ulna.

\section{KEY WORDS}

Intramedullary Nailing, Titanium Elastic Nailing, Dynamic Compression Plating
Corresponding Author: Dr. Chandan $S$. Department of Orthopaedics, Kurnool Medical College, Kurnool, Andhra Pradesh, India. E-mail: chandan.sgowda18@gmail.com

DOI: $10.14260 /$ jemds/2021/772

How to Cite This Article:

Basha AMI, Chandan S, Gajendra. A prospective comparative study of both bone forearm fracture in patients above twelve years of age treated with dynamic compression plating and intramedullary nailing at a tertiary care hospital in Kurnool, Andhra Pradesh. J Evolution Med Dent Sci 2021;10(45):3816-3820, DOI: 10.14260/jemds/2021/772

Submission 26-10-2021,

Peer Review 02-11-2021,

Acceptance 09-11-2021,

Published 10-12-2021.

Copyright (C) 2021 A.M. Ilias Basha et al. This is an open access article distributed under Creative Commons Attribution License [Attribution 4.0 International (CC BY 4.0)] 


\section{BACKGROUND}

Both bone forearm fractures in adults are more likely to be a result of high energy and communition is more common than those seen in children. Traditionally, both bone forearm fractures in children are treated closed much more often than both bone forearm fractures in adults. In general, complications are more common, and the prognosis is worse for displaced fractures and for open fractures. On the average, undisplaced fractures take six to eight weeks to heal, and displaced fractures take three to five months.

A function may be most obviously affected with loss of pronation/supination, ${ }^{1}$ and as many as half of patients with both bones forearm fracture will have loss of forearm pronation, which may or may not be functionally significant.

The common fixation methods include dynamic compression plating and intramedullary nailing. Successful management of these fractures needs understanding of fracture pattern, technique of fracture fixation, varieties of implant available for fixation and art of post-operative management.

Advances in the design of implants and minimally invasive operative tetchiness have shown uniformly good results even in complex fractures patterns. This prospective study was conducted to analyse the functional outcome of both bone forearm fracture above 12 years of age treated with dynamic compression plating and intramedullary nailing. This prospective study was conducted to analyse the functional outcome of both bone forearm fracture above 12 years of age treated with dynamic compression plating and intramedullary nailing.

\section{Aims and objectives}

1. To compare the results of treating a diaphyseal fracture of both bones forearm using osteosynthesis with dynamic compression plates and intramedullary nailing.

2. To study fractures healing and union rate in both methods.

3. To study the functional outcome in both techniques.

4. To study the complications of surgery.

\section{METHODS}

This is a prospective comparative study of 30 cases of diaphyseal fracture of both bones of forearm who attended casualty and OPD of Government General Hospital, Kurnool and were treated by surgical fixation with dynamic compression plating and intramedullary nailing between November 2018 to November 2020.

\section{Inclusion Criteria}

1. Diaphyseal fracture of both bones forearm in patients above 12 years of age.

2. Segmental fractures of the forearm.

3. Patients fit for surgery.

\section{Exclusion Criteria}

1. Compound fractures grade 3.

2. Malunited fractures.

3. Patients unfit and not willing for surgery.

Cases with closed fractures were immobilized in the above elbow POP slab as the initial management. Examination of injured limb was made and neurovascular status of the limb was assessed. And those with compound grade 1 were washed with copious amount of normal saline and initial care was given in emergency including thorough debridement of wound. Prophylactic treatment against tetanus was given and broad spectrum antibiotic were given to prevent the infection.

\section{Surgical Procedure}

Patients were given brachial plexus block using the supraclavicular approach. Nailing: Square nails/Tens nail were used for intramedullary nailing. Sizing of nail was determined prior to surgery.

The length of nail was determined by measuring the uninvolved limb directly. Ulna was measured with a measuring tape from the tip of olecranon to ulnar styloid and one (1) $\mathrm{cm}$ was subtracted from this measurement. The length of radius nail was determined by subtracting the 2.5 $\mathrm{cm}$. from the ulnar measurement.

Preoperatively, diameter was determined by measuring the narrowest diameter of the intramedullary canal on either anteroposterior (AP) or lateral view of the $\mathrm{x}$-ray of the fractured forearm.

During the surgery, Snug fitting nail was selected to avoid overriding of the oblique fracture. Patient was made to lie in supine on the OT table with the affected limb positioned on the arm board.

$\mathrm{C}$-arm was positioned over the affected limb. For ulnar nailing, $1 \mathrm{~cm}$ longitudinal incision was made over the tip of olecranon, triceps insertion was incised. Entry portal was made with the straight awl at a point 5 to $8 \mathrm{~mm}$ from the dorsal cortex and $5 \mathrm{~mm}$ from the lateral cortex over the olecranon.

No reaming was done. After reduction of the fracture by traction and manipulation under image intensifier, a nail of proper size was selected and inserted in the canal and hammered after reducing the fracture, leaving only $5 \mathrm{~mm}$ outside the bone end.

Fracture site was seen under image intensifier during hammering to avoid the distraction at the fracture site. Skin sutures were applied. For radius nailing, 1 to $1.5 \mathrm{~cm}$ incision was given extending distally from the dorsal margin of joint surface at a point just lateral to Lister's tubercle. The dissection was carried out between the extensor carpi radialis longus and extensor carpi brevis tendon.

The entry was made with the straight awl at radial styloid or listers tubercle. At the dorsal margin of joint, a straight awl was introduced at an angle of $45^{\circ}$ to joint surface.

After entering the bone 1 to $1.5 \mathrm{~cm}$, the angle of the awl was dropped to the axis of bone and continued another $1 \mathrm{~cm}$ in line with the medullary canal of bone. Rest of the technique was same as used for the ulnar nailing except that the nail was bent regularly to approximate the bow of the radius prior to the insertion. 


\section{Plating}

Both fractures were exposed and reduced before fixation of either. Fracture having less comminution was fixed first. Plates were applied using the AO principles. ${ }^{4}$ Volar Henry approach was used for fracture fixation. Ulna was exposed by subcutaneous approach. Plate was applied using the AO principles (Small fragment DCP/1/3 Tubular plate and 3.5 mm cortical screws).

\section{Post-Operative Care}

Immediately after surgery, the operated limb was immobilized in pop. The limb is elevated by using drip stand in the ward, and the neurological status is checked. Postoperative check dressing is done on 3rd day, and check X-ray is done without slab and slab reapplied.

Both groups of patients were discharged by 6th day and advised to review on 10th day for suture removal. The patient was given injection ciprofloxacin $100 \mathrm{ml}$ and injection gentamycin $80 \mathrm{mg}$ for three days and converted to oral antibiotics which were continued for ten days.

\section{Follow Up}

The patient was instructed to follow up on the 10th postoperative day. The sutures were removed. In patients with rigid fixation of compression plate, the plaster slab was discontinued, and active, gentle exercises were advised for the elbow, shoulder, wrist to the limit of tolerance and cautioned to avoid lifting weight and other strenuous activity.

Above elbow, the POP slab was applied in other patients for four weeks. The patients were followed up at a regular interval of four weeks at our hospital till union occurred and evaluation was done based on "MODIFIED GRACE AND EVERSMANN SCORING SYSTEM." scoring system. Elbow movements, supination and pronation were noted, and the union was assessed radiologically and clinically.

\section{Statistical Analysis}

Data was entered into Microsoft Excel data sheet and was analyzed using Statistical Package for Social Sciences (SPSS) 22 version software. Categorical data was represented in the form of frequencies and percentage. Chi-square test/Pooled chi square was used as test of significance for qualitative data. Continuous data was represented as mean and standard deviation. Student $\mathrm{t}$ test was used to test the level of significance between two groups for continuous variables.

$\mathrm{p}$ value (Probability that the result is true) of $<0.05$ was considered as statistically significant after assuming all the rules of statistical tests.

\section{Evaluation of Outcome 5}

The functional outcome was assessed using MODIFIED GRACE AND EVERSMANN SCORING SYSTEM. It includes the following parameters

Supination and Pronation

\begin{tabular}{|c|c|c|}
\hline Rating & Range of Movement & Score \\
\hline Excellent & $>80$ & 4 \\
\hline Good & 60 to 80 & 3 \\
\hline Fair & 40 to 60 & 2 \\
\hline Poor & $<40$ & 1 \\
\hline Sup & $\begin{array}{r}\text { ronation (Normal - Pr } \\
80 \text { Degrees Each) } \\
\end{array}$ & Supine \\
\hline
\end{tabular}

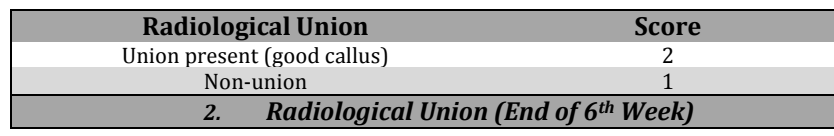

\begin{tabular}{|ccc|}
\hline Range & Result & Score \\
\hline Flexion $>120$ & Excellent & $\mathbf{4}$ \\
Flexion 100 to 120 & Good & $\mathbf{3}$ \\
Flexion 80 to 100 & Fair & $\mathbf{2}$ \\
Flexion $<80$ & Poor & $\mathbf{1}$ \\
\hline 3. & Range of Movement-Elbow & \\
\hline
\end{tabular}

\begin{tabular}{|ccc|}
\hline Result & Score \\
Excellent & 10 and above \\
Good & & 8 to 9 \\
Fair & & 6 to 7 \\
Poor & & Less than 5 \\
\hline \multicolumn{2}{|c|}{ 4. Final Analysis } \\
\hline
\end{tabular}

\section{RESULTS}

\section{Functional outcome}

\begin{tabular}{|c|c|c|c|c|c|c|}
\hline $\begin{array}{l}\text { Sl. } \\
\text { No. }\end{array}$ & Parameter & & $\begin{array}{l}\text { Plating } \\
\text { Group }\end{array}$ & $\begin{array}{l}\text { Nailing } \\
\text { Group }\end{array}$ & $\begin{array}{c}\mathbf{P} \\
\text { Value }\end{array}$ & Significance \\
\hline 1. & Mean age & & 15 & 15 & $P>0.05$ & Not significant \\
\hline 2. & Sex & $\begin{array}{l}\text { Male } \\
\text { Female }\end{array}$ & $\begin{array}{l}08 \\
07\end{array}$ & $\begin{array}{l}07 \\
08\end{array}$ & $P>0.05$ & Not significant \\
\hline 3. & Side & $\begin{array}{l}\text { Right } \\
\text { Left }\end{array}$ & $\begin{array}{l}09 \\
06\end{array}$ & $\begin{array}{l}11 \\
04\end{array}$ & $P>0.05$ & Not significant \\
\hline 4. & $\begin{array}{l}\text { Mechanism } \\
\text { of injury }\end{array}$ & $\begin{array}{c}\text { RTA } \\
\text { Self-fall } \\
\text { Assault }\end{array}$ & $\begin{array}{l}10 \\
02 \\
03\end{array}$ & $\begin{array}{l}10 \\
02 \\
03\end{array}$ & $P>0.05$ & Not significant \\
\hline 5. & Level of fracture & $\begin{array}{c}\text { Upper/3 } \\
\text { Middle/3 } \\
\text { Lower/3 }\end{array}$ & $\begin{array}{l}03 \\
11 \\
01\end{array}$ & $\begin{array}{l}04 \\
08 \\
03\end{array}$ & $P>0.05$ & Not significant \\
\hline 6. & $\begin{array}{c}\text { Closed or } \\
\text { open }\end{array}$ & $\begin{array}{l}\text { Closed } \\
\text { Open }\end{array}$ & $\begin{array}{l}15 \\
01\end{array}$ & $\begin{array}{l}10 \\
04\end{array}$ & $P>0.05$ & Not significant \\
\hline 7. & $\begin{array}{l}\text { Pattern of } \\
\text { fracture }\end{array}$ & $\begin{array}{l}\text { Transverse } \\
\text { Oblique } \\
\text { Spiral } \\
\text { Communited } \\
\text { Segmental }\end{array}$ & $\begin{array}{c}10 \\
02 \\
01 \\
0 \\
0\end{array}$ & $\begin{array}{c}10 \\
04 \\
01 \\
01 \\
1\end{array}$ & $P>0.05$ & Not significant \\
\hline 8. & $\begin{array}{c}\text { Associated } \\
\text { injury }\end{array}$ & $\begin{array}{l}\text { Clavicle } \\
\text { Humerus } \\
\text { Contralateral } \\
\text { forearm } \\
\text { Hand } \\
\text { Others }\end{array}$ & $\begin{array}{c}02 \\
01 \\
0 \\
2 \\
0\end{array}$ & $\begin{array}{c}02 \\
02 \\
0 \\
1 \\
0\end{array}$ & $P>0.05$ & Not significant \\
\hline 9. & $\begin{array}{c}\text { Time for } \\
\text { operation (days) }\end{array}$ & & 7 & 4 & $P>0.05$ & Not significant \\
\hline 10 & $\begin{array}{c}\text { Union } \\
\text { (weeks) }\end{array}$ & & 9.20 & 7.67 & $\mathrm{P}>0.05$ & Not significant \\
\hline
\end{tabular}

The present study was conducted at Government General Hospital, Kurnool from November 2018. A total of 30 study subjects were analyzed in the present study including 15 subjects in dynamic compression plate and 15 subjects in intramedullary nailing.

The functional forearm is very essential for achieving full range of motion. Fractures of both bones forearm may result in severe loss of function unless adequately treated. The relationship of the radio humeral, radioulnar, ulnohumeral radiocarpal, distal radioulnar joint and the interosseous space must be perfect. Otherwise, some functional impairment will result. 6

In addition to regaining length, opposition axial alignment, achieving rotational alignment is necessary, if good range of pronation and supination is restored. ${ }^{7}$ Malunion and non-union frequently occur because of difficulty in maintaining reduction of radius and ulna in the presence of pronating and supinating muscles that have ambulatory as well as rotational influences. Because of these factors, surgical management for displaced diaphyseal fractures in the adult is generally accepted. 
A satisfactory device for internal fixation is that it must hold the fracture rigidly, eliminating as completely as possible, angular and rotatory motion. This can be accomplished by either a strong intramedullary nail or dynamic compression plate.

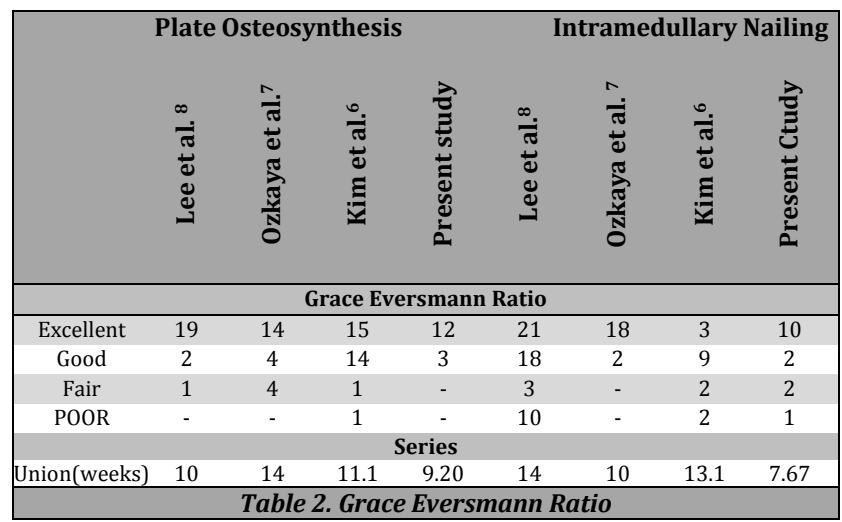

\section{DISCUSSION}

\section{Fracture Union Time}

The time taken for union in DCP group was 9.20 weeks, and in IMN group it was 7.67 weeks. It could be seen that union time was lesser in the IMN group, but statistically, it was nonsignificant. Even the time taken for the complete return of range of movements was 12 weeks in DCP and 10.53 weeks in IMN group with a statistically insignificant p-value. But in both, the group's total time taken for the return to normal work was almost the same in both the groups.

The total time taken for the union was found to be between 8 to 10 weeks in $93.3 \%$ among DCP group, and in the IMN group, $86.7 \%$ unions were seen between 5 to 7 weeks. The p-value was found to be statistically significant between the two groups and the time of union.

Among the subjects, delayed union was seen in $1(6.7 \%)$ subject in both the groups. Infection was seen in $2(13.3 \%)$ subjects in the DCP group and $1(6.7 \%)$ in the IMN group. Stiffness was seen in only 1 (6.7\%) study subjects i.e. in DCP group only. Extensor pollicis longus (EPL) injury, non-union and infection were seen in only $1(6.7 \%)$ of the study subjects in the IMN group.

In the study done by Sreejith et al. ${ }^{9}$ too, delayed union was seen in the IMN group only when compared with DCP group.

In the study done by Venkataraman S, et al. ${ }^{10}$ delayed union was seen in both the dtudy groups of DCP and IMN, non-union was seen only in $2(6.7 \%)$ subjects in IMN group which is similar to our study findings. The DCP group complete union was achieved in 23.39 weeks and in IMN group it was 28.89 weeks which is much higher when compared to our study findings.

In most of the studies based on the literature review, the union of bones in DCP group is between $80 \%$ to $100 \%$ and the average time taken for the recovery varies from 7.4 weeks to 33 weeks. In IMN group, the average union rate was 90 to $100 \%$ between 10 to 32 weeks. $^{7}$

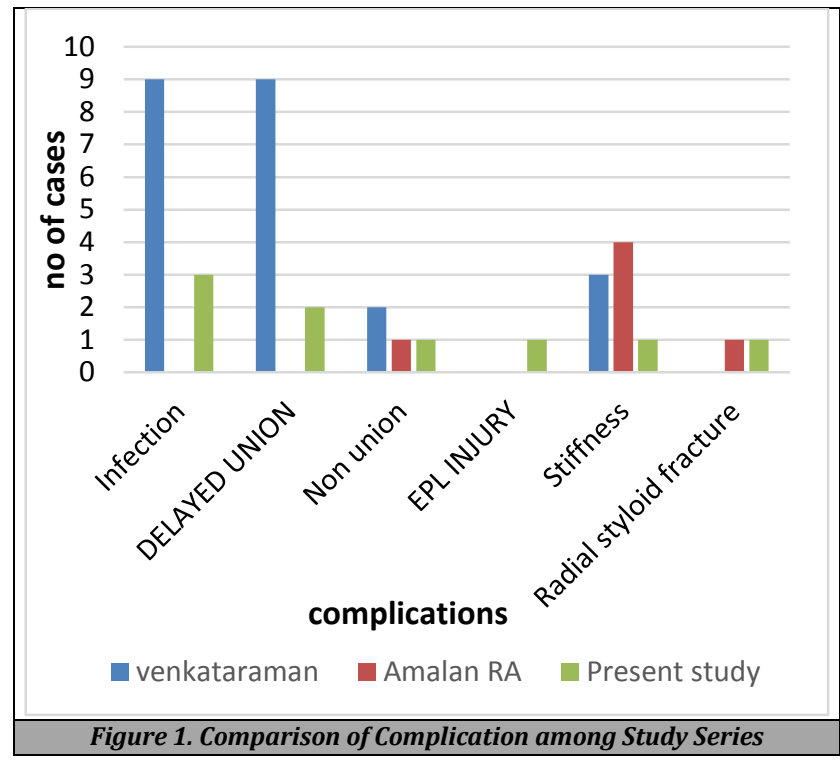

\section{Movements}

It was observed that movement (supination and pronation) was found to be excellent in $80 \%$ of the subjects in the DCP group and $73.3 \%$ in the IMN group. At the elbow, joint movement was found to be excellent in $80 \%$ of study subjects in the DCP group and IMN group.

The restoration of movements at elbow and wrist joint depends mainly on the anatomical realignment and restoration of the radial bow. As intramedullary nailing was performed in closed reduction, restoration of the radial bow was difficult, and this resulted in less percentage of excellent results in the intramedullary nailing.

\section{CONCLUSIONS}

Fractures of both bones are one of the commonest fractures being reported to orthopaedic surgeons. Early fixation, followed by intense physiotherapy produced excellent results. Fixation with plate osteosynthesis has stood the test of time and provides excellent fixation. The advantages of intramedullary fixation are preservation of fracture hematoma, early mobilization, can be done as a day care procedure, less postoperative morbidity, smaller incisionhence better cosmesis, last but not the least, since there is no axial loading, the chances of implant failure is very less.

Even though plate osteosynthesis is still the most commonly used form of fixation in both bone forearm fractures, both titanium elastic nail and intramedullary nail fixation are relatively newer techniques which offer viable and more efficient alternative especially in fixation of fractures involving shafts of radius and ulna.

Data sharing statement provided by the authors is available with the full text of this article at jemds.com.

Financial or other competing interests: None.

Disclosure forms provided by the authors are available with the full text of this article at jemds.com. 


\section{REFERENCES}

[1] Anderson LD, Sisk D, Tooms RE, et al. Compression plate fixation in acute diaphyseal fractures of the radius and ulna. J Bone Joint SurgAm 1975;57(3):287-96.

[2] Moed BR, Kellam JF, Foster JR, et al. Immediate internal fixation of open fractures of the diaphysis of the forearm. J Bone Joint Surg Am 1986;68(7):1008-17.

[3] Matthews LS, Kaufner H, Garver DF, et al. The effect on supination pronation of angular malalignment of fractures of both bones of the forearm. J Bone Joint Surg Am 1982;64(1):14-17.

[4] Muller ME, Allgower M, Schenider R, eds. Manual of internal fixation; techniques recommended by the AOASIF group $3^{\text {rd }}$ edn. Berlin: Springer 1991.

[5] Grace TG, Eversmann WW. Forearm fractures: treatment by rigid fixation with early motion. J Bone Joint Surg Am 1980;62(3):433-8.
[6] Kim SB, Heo YM, Yi JW, et al. Shaft fractures of both forearm bones: the outcomes of surgical treatment with plating only and combined plating and intramedullary nailing. Clin Orthop Surg 2015;7(3):282-90.

[7] Ozkaya U, Kilic A, Ozdogan U, et al. Comparison between locked intramedullary nailing and plate osteosynthesis in the management of adult forearm fractures. Acta Orthop Traumatol Turc 2009;43(1):14-20.

[8] Lee SK, Kim KJ, Lee JW, et al. Plate osteosynthesis versus intramedullary nailing for both forearm bones fractures. Eur J Orthop Surg Traumatol 2014;24(5):769-76.

[9] Sreejith GS, Gunaki RB, Kishor S, et al. A comparative study of both bone forearm fractures treated with intramedullary nailing vs plating in adults. International Journal of Orthopaedics Sciences 2019;5(2):881-5.

[10] Venkataraman S, Ethiraj P, Naik AHS, et al. Diaphyseal fractures of the forearm in adults, comparative study of dynamic compression plate versus intramedullary nail. Int J Res Orthop 2019;5(5):916-20. 